\title{
Considerações sobre o despotismo colonial, e a gestão centralizada da violência no Império colonial francês*
}

\section{Considerations about colonial despotism, centralized management and violence in french colonial Empire}

\author{
JEAN-MICHEL MABEKO-TALI* \\ Departmento de História \\ Howard University \\ Washington (DC) \\ Estados Unidos
}

RESUMO O estudo da questão do trabalho forçado na era colonial implica, inequivocamente, a análise do sistema de violência colonial em si, como um todo sistêmico e estrutural. Com efeito, estes sistemas coloniais, na sua implementação, e apesar das reformas laborais que marcaram a evolução dos impérios coloniais a seguir à Il Guerra Mundial, assentavam em filosofias que, embora aparentemente diferenciadas, tinham como objetivo primordial

* Artigo recebido em: 22/06/2013. Autor convidado.

** Professor \& Graduate Faculty of African History. College of Arts and Sciences. Um agradecimento à Dra. Isabel P. B. Féo Rodrigues, Universidade do Massachusetts, que teve a paciência de fazer a revisão do português que escolhi como língua para a elaboração deste texto. Contato: jmabeko-tali@howard.edu; talilda@yahoo.com. 
rentabilizar ao máximo as colônias e torná-las lucrativas em beneficio exclusivo da economia metropolitana. Nas páginas que se seguem, pretende-se examinar como o sistema colonial francês quando comparado com seu homólogo britânico, e ainda o belga, estruturou o sistema de violência que serviu de base funcional para que o trabalho forçado pudesse render e articular-se de modo eficiente com os objetivos econômicos coloniais. Neste âmbito, procuraremos analisar comparativamente a economia política da violência que caracterizou o sistema laboral nas colônias de modo geral.

Palavras-chave colonialismo europeu, sistema laboral, violência, Congo

ABSTRACT The study of the issue of forced labor in colonial implies unequivocally system analysis of colonial violence itself, as a whole systemic and structural. Indeed these colonial systems, implementing, and despite labor reforms that marked the evolution of the colonial empires after the Second World War, were based on philosophies that although seemingly different, had the primary objective to best effect the colonies and make them profitable for the benefit exclusive of the metropolitan economy. In the pages that follow, we intend to examine how the French colonial system when compared with his British counterpart, and also the Belgian structured system of violence that served as a functional basis for the forced surrender and could articulate so efficient with the colonial economic goals. In this context, we seek to comparatively analyze the political economy of violence that characterized the labor system in the colonies generally.

Keywords european colonialism, labor system, violence, Congo

\section{Considerações gerais sobre a estruturação da violência colonial}

O debate sobre os diferentes sistemas coloniais tem ao menos um elemento de consenso: britânico ou francês, belga, português ou espanhol, todos eles eram baseados em idênticos fundamentos. E o primeiro desses fundamentos era o fato de que se tratava de uma violência virada para um funcionamento eficaz do sistema econômico, única justificativa historicamente objetiva do processo colonial. Desta forma, as diferenças apenas provieram do modo de estruturar a violência. Em alguns casos, esta violência era descentralizada. Foi fundamentalmente o caso do sistema britânico chamado de indirect rule. O indirect rule tem sido às vezes apresentado como uma forma menos brutal de gestão da ordem colonial, por ter recorrido a poderes ou figuras indígenas locais na administração das colônias. Importa, com efeito, recordar que o real propósito da sua instituição foi de, por um lado, resolver questões práticas de funcionamento administrativo, e, por outro lado, diminuir as despesas inerentes ao funcionamento administrativo das 
colônias. Ou seja, tal sistema nasceu da "simples necessidade econômica e política"1 de se descentralizar o trabalho e as estruturas burocráticas de forma a torná-las mais eficientes. Dito de outro modo, o sistema britânico de indirect rule nasceu não de uma simples vontade de integrar os autóctones africanos (ou indianos) na gestão da colônia, mas tão-somente, de explorar a mão de obra local reduzindo assim os custos administrativos da burocracia colonial. Nem tampouco se tratou de um sistema virado para um tratamento menos cruel dos colonizados. No entanto, o indirect rule abriu indiretamente brechas sistêmicas que permitiram aos colonizados forjar identidades específicas dentro do próprio sistema colonial, e ao mesmo tempo deu lugar a um relacionamento no qual a violência colonial acabou sendo menos direta em certas circunstâncias, salvo quando se tratasse de esmagar e controlar as rebeliões dos colonizados.

No caso que nos concerne aqui, na questão do trabalho forçado, o indirect rule tinha como vício a partilha da violência com agentes autóctones da força pública. Ao criarem tropas auxiliares indígenas, milícias ou Force publique (no caso belga), como braço repressivo do sistema, todos os sistemas coloniais acabariam por instaurar o que viria a ser o braço armado dos futuros Estados independentes - cuja "parcial" exceção foi o caso dos estados onde a libertação seria obtida mediante lutas armadas anticoloniais, ao fim das quais, de princípio e numa larga medida, seriam as guerrilhas vitoriosas que trariam das matas ou das montanhas o embrião das forças armadas e da nova ordem política. A este embrião se juntariam os núcleos reminiscentes das forças indígenas do estado colonial, mais ou menos largos consoante os casos e os níveis de compromisso entre o núcleo oriundo da guerrilha e o sistema repressivo colonial. Seja como for, no caso britânico, podemos concordar com Mahamood Mamdani quanto ao fato de que houve deliberadamente uma "descentralização despótica" da violência colonial por meio do indirect rule:

O gênio do domínio britânico em África (...) foi procurar civilizar as comunidades, não o indivíduo (...). A violência quotidiana do sistema colonial foi incorporado nas Autoridades Nativas no estado local e não no poder civil central. (...) mesmo assim, não devemos esquecer que a autoridade costumeira local era reforçada e sustentada pelo poder civil central. ${ }^{2}$

Este autor conclui sua reflexão sobre o caso britânico dizendo: "Colonial system was highly decentralized". ${ }^{3}$ Uma descentralização que era simbo-

1 ALEMIKA, Etannibi E. O. Federalism and the Police in Nigeria. In: GANA, Aaron Tsado; EGWU, Samuel G. Federalism in Africa: the imperative of democratic development. Princeton, NJ; Asmara, Eritreia: Africa World Press, 2003, p.143.

2 "The genius of British rule in Africa (...) was in seeking to civilize African as communities, not as individuals (...). The day-to-day violence of colonial system was embedded in customary Native Authorities in the local state, not in civil power at the center. (...) Yet we must not forget that customary local authority was reinforced and backed up by central civil power." MAMDANI, Mahamood. Citizen and subject: contemporary Africa and the legacy of late Colonialism. Princeton, New Jersey: Princeton University Press, 1996, p.22-23.

3 MAMDANI, Mahamood. Citizen and subject, p.22-23. 
lizada e resumida pelos "três pilares" do indirect rule que eram: a Native Authority (que geria os assuntos "costumeiro" dos nativos), a Native Treasury (encarregada de gerir as finanças da administração local), e a Native Court (encarregada dos assuntos jurídicos das comunidades nativas). Ou seja, uma estrutura que, de certo modo, acabava delegando poderes locais sob responsabilidades de autoridades nativas, e, deste modo, diluindo o poder direto, rígido, do governador, além de poupar meios financeiros e recursos humanos metropolitanos - mesmo se isto tudo acabava sendo muito relativo no cômputo global do sistema de ocupação e opressão coloniais.

A questão torna-se mais problemática e discutível quando se trata do modelo colonial direto, e no caso do império colonial francês. Neste último, com efeito, o administrador territorial, ou governador, constituía um autêntico déspota: ele era o topo de um poder vertical, centralizado, que dirigia com uma mão férrea o território colonial sob sua jurisdição. É certo que ele também, tal como no sistema de indirect rule britânico, recorria a autoridades tradicionais, ora pré-existentes, ora (mais frequentemente) nomeadas pelo poder colonial, e que tinham um semblante de autoridade sobre os cercles (círculos), ou seja, pequenas localidades territoriais, no caso da África ocidental francesa, os cantons, ou as aldeias, entre as diferentes estruturas intermediárias que compunham a repartição administrativa dos territórios sob jurisdição. Mas neste caso, ao contrário do modelo britânico, a autoridade conferida aos chefes "tradicionais" de tais micro entidades era mais simbólica do que efetiva. Na prática, porém, essa autoridade acabava colocando esses chefes num beco sem saída.

\section{Ciclo de zelo e encadeamento da violência: o beco sem saída das chefias africanas}

Com efeito, tanto num caso como noutro, tais atribuições colocavam o dito poder "tradicional" numa encruzilhada infernal, apanhado que se encontrava na armadilha de ter que manter o controle das populações sob vigilância da autoridade colonial. Situação esta que levava a que, com o tempo, ele fosse perdendo consideração aos olhos das populações colonizadas que o assimilavam, de resto com a propriedade, ao sistema opressor, aos trabalhos forçados, às monoculturas compulsivas de produtos para o mercado europeu ou americano, a maus-tratos e humilhações de toda a ordem inerentes ao sistema colonial como um todo. Isto levou na prática à destruição simbólica e efetiva do verdadeiro poder tradicional, à banalização da função e de um poder outrora sagrado, honroso. Acrescido à introdução de valores religiosos judeu-cristãos, eurocêntricos nas suas práticas cultuais e espirituais, isto tudo acabava por se juntar a um ciclo de violência que misturava violência física, cultural e espiritual, num conjunto que fazia literalmente o mundo ancestral desabar, "cair em pedacinhos", 
como mostrou na sua magistral obra literária, o mestre da literatura africana, Chinua Achebe. ${ }^{4}$

Falando do caso do sistema colonial belga (que se pode classificar como direct rule com veleidades pouco consequentes de indirect rule), Nzongola-Ntalanji mostra com efeito como o regime colonial iria utilizar de forma viciosa os chefes africanos: primeiro destituindo-os dos cargos que lhes cabiam por leis costumeiras, e depois, quando perceberam que seria mais útil para os interesses coloniais servir-se deles, acabando por instrumentalizá-los como auxiliares. Como em todo lado, esta instrumentalização acabou desprestigiando os chefes juntos das suas comunidades, colocando o próprio poder colonial numa situação ambígua. Por um lado, tinham que aceitar que esses representantes do poder tradicional se tornassem poderosos, o que não era do interesse colonial. Por outro lado, a falta de confiança que as populações africanas depositavam nesses chefes não era tampouco do interesse da administração colonial pois eles representavam o melhor vínculo que as autoridades podiam obter com as populações rurais. Conforme Georges Nzongola-Ntalanja explica:

A administração colonial acabou por estar preocupada com a questão do declínio do prestígio dos chefes, e em 1900, um relatório dirigido ao Rei Leopold descrevia uma nova visão da administração local sugerindo que se encontrasse um intermediário popular, com suficiente influência sobre as populações de forma a manter a sua obediência. Para os recém esclarecidos colonialistas, este intermediário era o chefe tradicional, única pessoa capaz de gerar tal obediência. ${ }^{5}$

Contudo, a subjugação do chefe local ao poder colonial significava mais zelo da sua parte no uso do seu prestígio, o que se traduzia portanto na imposição crescente de exigências às populações por ele chefiadas. Assim sendo, e no cumprimento das exigências das autoridades coloniais, as chefias locais não só impunham trabalhos forçados e agro-culturas compulsivas como também recrutavam das suas próprias comunidades os indivíduos que iriam servir nas milícias coloniais em guerras de "pacificação" noutras colônias ou como conscritos nos exércitos coloniais durante as duas Guerras Mundiais. Pelo que, por fim, voltava-se à estaca zero, com revoltas populares, e desprestígio subsequente do chefe-instrumento.

Jean Suret-Canale chamou a este processo sistêmico de destruição política das chefias tradicionais africanas de tache d'huile (mancha de óleo): uma mancha que, usando uma base estrutural de apoio inicial, acabou por

ACHEBE, Chinua. Things fall apart. New York: Anchor Books, 1994.

5 "The colonial administration became preoccupied with the question of declining chiefly prestige, and a 1900 report to King Leopold described the new approach to local administration as that finding a popular intermediary with enough influence on the masses to maintain their obedience. For the newly enlightened colonialists, that intermediary was the traditional chief, the only person then capable of generating such obedience"; NZONGOLA-NTALANJA, Georges. The Congo from Leopold to Kabila: a people history. London/New York: ZED Books, 2002, p.35. 
tornar irrelevantes as figuras do poder tradicional, diminuindo sua capacidade de resistência, e permitindo desta forma que o poder colonial pudesse "tornar-se dono da totalidade do país". ${ }^{6}$ Ainda no caso do Congo belga, o chefe que não cumprisse com as obrigações que lhe cabiam sabia o que the esperava: humilhação pública, seu aprisionamento, o da sua família ou "de qualquer habitante apanhado ao acaso, mais frequentemente mulheres". ${ }^{7}$ Um processo que representava, de fato, a "morte política" do chefe. No caso do império colonial francês, tal processo de "morte política" dos poderes tradicionais africanos serviu também de base para a estruturação e efetivação do sistema do trabalho forçado. O medo da autoridade e dos castigos implicava e induzia o excesso de zelo no exercício dos poderes nominais e coercitivos de que estavam incumbidos os chefes tradicionais: uma situação de beco-sem-saída, em que eles deveriam corresponder às exigência de um sistema vertical na sua essência, no topo do qual se encontrava o poder despótico e centralizador do governador ou administrador territorial.

\section{Centralização da violência: a estruturação do despotismo colonial}

Na sua estruturação, o centro absoluto do poder colonial francês era representado pela residência do governador ou do administrador territorial. Abaixo deste, havia funcionários coloniais, executores de uma autoridade rígida, vertical; havia a seguir os chefes africanos das diferentes subdivisões territoriais (cercles (círculos), cantos (cantões), villages (aldeias)). E, como electrões semi-livres, havia os recrutadores europeus de mão de obra indígena, e oficiais de lobbies ao serviço de empresas privadas ou companhias concessionárias europeias, cuja atuação no terreno, como veremos, acabava muitas vezes por escapar mesmo ao controle das legislativas laborais metropolitanas. Tal estruturação traduzia-se, na prática, por um sistema baseado fundamentalmente na intolerância, e que levava a que se castigasse da maneira mais cruel possível não apenas o aldeão desobediente, mas também todos os que se furtassem à corveia, ${ }^{8}$ que faltassem ao pagamento dos diversos tipos de impostos coloniais, ou que não tivessem produzido a quota de borracha ou de marfim requerida por força.

Em certas circunstâncias, e frequentemente, o próprio chefe africano da circunscrição que falhasse em produzir o requerido número de trabalhadores destinados ao trabalho coercitivo, ou à implementação das culturas obrigatórias destinadas às exportações da colônia, acabava sendo vítima

6 SURET-CANALE, Jean. L'Afrique Noire: I'ère coloniale. Paris: Éditions Sociales, 1962, p.93-120.

7 TSHIMANGA, Charles. Jeunesse, formation et société au Congo-Kinshasa, 1890-1960. Paris: L'Harmattan, 2001, p.39-40.

8 No caso do antigo Congo belga, por exemplo, ainda sob a era das companhias concessionárias sob o chamado "Estado Livre do Congo" do rei Leopold II da Bélgica, os castigos eram mais cruéis ainda, indo das torturas mais inimagináveis à amputação da mão. Ver HOCHSCHILD, Adam. King Leopold's ghost. Boston/New York: Houghton Mifflin Company, 1998. 
do castigo e da desconsideração. Isto traduzia-se inclusive por humilhações públicas por parte do sistema que o tinha colocado no lugar de chefia "tradicional". Pode-se compreender, assim, a razão do sistema colonial proceder à instauração, onde e quando intendesse, de novas chefias, rotuladas de "tradicionais", em substituição de antigas e genuínas entidades tradicionais. De qualquer modo, quem fosse detentor de tal precário poder acabava inevitavelmente sendo arrastado num ciclo de violência sistêmico. E o acatamento cego das ordens e das exigências do administrador colonial se tornava um meio de auto-preservação e de proteção da família. A insegurança de tal status estrutural acabava com efeito criando um sistema de excesso de zelo por parte de quem tivesse um mínimo de poder, sob o olhar vigilante do poder colonial. Mais ainda, os vícios estruturais deste sistema laboral repousavam em vários pilares de incentivo individual, tal como a promoção laboral e estatutária através de bônus prometidos aos funcionários e recrutadores europeus ao serviço das companhias privadas operando nas colônias. Concomitantemente, a corrida para o aumento da produtividade, e portanto dos lucros, acrescia o ciclo de violência.

Por outras palavras, as companhias coloniais queriam mais rendimentos para obterem maiores benefícios; os seus recrutadores europeus queriam mais braços para o aumento do rendimento (numa economia em que a força humana era ainda o motor do rendimento), pois disto dependia sua autopromoção e maximização de bônus. ${ }^{9}$ Para tal, exerciam pressão sobre os chefes e utilizavam métodos cruéis no intuito de arrebanhar mais trabalhadores. Por sua vez, os chefes das comunidades locais, impostos ou não pelo poder colonial, assim como os Kapitas (o equivalente, na África Equatorial francesa aos 'capatazes' no sistema colonial português), tinham de encontrar e entregar a mão de obra requerida se quisessem salvaguardar a sua própria sobrevivência estatutária e social, ou mesmo a sua segurança física face à ganância dos recrutadores.

Tudo isto desembocava num ciclo cada vez mais acrescido de excesso de zelo e de crueldade à medida que se descia a hierarquia do sistema laboral colonial. Um ciclo vicioso que atingiu sem dúvida o seu clímax e requinte no Congo belga: além de corte de mão, havia o sistema de chicoteadas administradas duas vezes por dia, em público, com o infeliz castigado completamente desnudado, e estendido na praça de hastear a bandeira belga - antes da cerimônia do hasteamento desta, para a "sessão matinal", e às 14 horas para a segunda "sessão". ${ }^{10}$ O próprio chefe tradicional sabia que poderia cair nesta categoria se não se mostrasse zeloso, e se não cumprisse com as suas obrigações para com as exigências da

9 COOPER, Fredrick. Decolonization and African society: the labor question in French and British Africa. Cambridge: Cambridge University Press, 1996

10 NZONGOLA-NTALANJA, Georges. The Congo from Leopold to Kabila, p.37 
administração colonial. Isto nutriu, sem dúvida alguma, o ciclo do zelo, como veremos a seguir.

Citando um relatório escrito em 1918 por um funcionário colonial britânico, assistente de distrito no Quênia, Cooper diz que o referido funcionário teria notado que "o sucesso para se conseguir que os chefes africanos fornecessem trabalhadores para os colonos brancos" "depended on how far he could be induced to exceed his instructions". ${ }^{11}$ Esta "indução", ainda segundo o mesmo autor, significava simplesmente coerção, o que teria chocado os lobbies antiescravistas britânicos quando tal afirmação chegou aos ouvidos da opinião pública como sinônimo de trabalho coercitivo de tipo escravista: "Isto ultrapassou os limites daquilo que o lobby antiescravista britânico tinha estado a chamar de 'escravismo por outro nome'".

Mas isto não parece ter suprimido a prática, por longos anos ainda, no império britânico. E os africanos sob o indiret rule não pareciam nutrir qualquer ilusão quanto à natureza do regime de trabalho forçado a que estavam submetidos, pelo que o termo indirect rule acabava perdendo o sentido para eles. Falando ainda do caso dos britânicos no Quênia, Cooper sublinha com efeito:

Mas os africanos da região utilizavam a palavra "chibaro" - o que significava escravo nas línguas locais - para designarem este tipo de trabalhadores. 0 recrutamento, tal como a escravatura, implicava uma aplicação da disciplina diferente do "castigo de saque" que está na base da disciplina do trabalho capitalista. Trabalhadores com contratos fixos estavam retidos por sanções penais contra deserções, e tinham poucos incentivos positivos. ${ }^{12}$

Ou seja, o indirect rule não significou menos violência nem ausência de trabalho forçado perto de regime escravista, num regime de rigor em que o "chibaro" nem podia decidir deixar ou desertar um trabalho efetuado em tais condições. A própria instituição do Pass criada como instrumento de controle da movimentação populacional, ou seja, mais concretamente, instrumento de controle da força laboral - prática que iria generalizar-se em todas as colônias - nem Ihe permitia circular livremente, caso decidisse abandonar o trabalho praticamente escravo a que estava sujeitado. Nisto serviria a mobilidade dada às forças de repressão e de controle territorial: as milícias coloniais.

11 COOPER, Fredrick. Decolonization and African society, p.43.

12 But the Africans in the region used the word "chibaro" - meaning slave in local languages - to refer to such workers. Recruitment, like slavery, implied an approach to discipline distinct from "sanction of sack" that underlay capitalist work discipline. Workers on fixed contracts were held in place by penal sanctions against "desertion" and had few positive incentives; COOPER, Fredrick. Decolonization and African society, p.44. 


\section{Milícias, militarização e teatralização do poder colonial: uma cadeia de crueldades}

As milícias coloniais viriam a ser o instrumento militar para a aplicação de tal sistema de violência multidimensional de triste memória. Na África Central, foram os famigerados mbulu mbulu (conforme eram chamados nas línguas locais de ambos os Congos, belga e francês), também apelidados de Tuluku ('Turcos') pelas populações locais, na zona norte da bacia do Congo francês, certamente em referência aos milicianos coloniais vindos da África do Norte ou mesmo da África ocidental francesa. Essas eram milícias de fato formadas muitas vezes por africanos trazidos de outros territórios coloniais, nomeadamente da África ocidental, entre os quais os malfadados Tirailleurs sénégalais (atiradores ou fuzileiros senegaleses), ${ }^{13}$ como eram genericamente conhecidos.

Os motivos de tais "importações" de agentes da aplicação da violência colonial tinham fundamentalmente a ver com o receio de que as milícias locais poderiam mais facilmente resvalar numa atitude de condescendência e flexibilidade, ou de formar alianças e cumplicidades particularmente em caso de parentesco ou proximidade etnolinguística entre ambos os milicianos e as populações locais. Mais terre-à-terre, porém, a questão da escassez da mão de obra em certas regiões da África Equatorial francesa, que fora uma constante, para o desespero das companhias concessionárias no caso do Congo francês, ${ }^{14}$ justificou importações de trabalhadores de outras colônias tanto para a produção mineira, agrícola e de exploração florestal (indústria madeireira), como para a construção de infraestruturas chaves da economia colonial. A construção pelos franceses, de 1931 a 1934, do Caminho de Ferro Congo-Océan (CFCO), por exemplo, viu a importação de milhares de trabalhadores da África Ocidental, da Indochina e da China, para levar a cabo esta obra que seria uma autêntica hecatombe humana ("um morto por travessa" da via férrea, segundo consta a memória popular deste empreendimento colonial de suma importância para a conexão entre o rio Congo e o Oceano Atlântico). A construção de infraestruturas portuárias em Boma e Matadi, ou do caminho de ferro que ligava a primeira capital do Congo belga (Boma) a Kinshasa, por exemplo, também levou à importação de trabalhadores da África Ocidental tanto francesa como inglesa. Muita

13 Embora originalmente do território colonial do Sénégal (daí a denominação original), o nome "Tirailleurs sénégalais" acabou sendo genérico na designação das milícias e tropas da África negra francesa, que partipariam de todas as operações de "pacificação" dos territorios conquistados, ou de repressão de sublevações anticoloniais no continente desde o século XIX. Pode-se citar, por exemplo, a sua participação na repressão em Madagáscar (1947), nos Camarões (1955), mas também durante a guerra na Indochina (1945-1954), e como soldados nas duas guerras mundiais ao lado das tropas metropolitanas.

14 COQUERY-VIDROVITCH, Catherine. Le Congo au temps des grandes compagnies concessionnaires, 1898-1930. v.1, Paris: Editions de l'Ecole des Hautes Etudes en Sciences Sociales, 2001, p.15. 
dessa gente iria também nutrir o recrutamento para a Force Publique, instrumental para o policiamento (e a repressão) na colônia belga.

Seja como for, a estruturação do sistema de aplicação da violência nas colônias francesas correspondia, sem dúvida alguma, a um despotismo local, cujo modelo iria ser reproduzido pelos estados independentes. ${ }^{15} \mathrm{E}$ neste sistema, quanto mais se descesse na escala de responsabilidades, maior era a violência da aplicação do sistema repressivo. Era como se, a cada escala menor de responsabilidade, cada um temesse ora pela sua própria sobrevivência material e ascensão social (para os funcionários coloniais, e os recrutadores e lobbistas europeus ao serviço das companhias privadas, face ao poder central e despótico do governador, e este último face ao poder centralizador da metrópole); ora pela sua sobrevivência tanto material como física no caso dos chefes locais, e milicianos coloniais. Pelo que, cada um devesse dar prova da sua lealdade para com este despotismo central multiplicando de forma excessivamente zelosa as formas e os níveis de aplicação da violência. A crueldade das milícias coloniais parece justificar-se por esta dialética repressiva complexa inerente ao sistema repressivo de qualquer poder absoluto. Na comparação de Suret-Canale entre a metrópole e as colônias, sobressaía esta cadeia de estruturação dialética da violência colonial:

Ao despotismo ministerial (na metrópole), responde, localmente (i.e. nas colônias) o despotismo dos governadores e administradores. O despotismo dos agentes inferiores só tem como limite o despotismo dos seus superiores. ${ }^{16}$

Também no caso belga, como mostra Nzongola-Ntalanji, este despotismo estava repartido através de uma hierarquização administrativa territorial, mas com igual poder de controle, entre os governadores provinciais, os chefes de distritos, e os administradores territoriais: todos eles eram proconsuls e exerciam "um verdadeiro despotismo e de total controle" sobre os territórios sob sua jurisdição:

Despotismo e controle total eram, pois, mais evidentes a nível do território, geralmente uma vasta área que compreendia várias chefias tradicionais. Aqui, o administrador ocupava-se virtualmente de tudo, inclusive das tarefas essenciais de guarda-livro, manutenção da ordem, cobrança de impostos, recrutamento para o trabalho, conscrição, a administração da justiça e do serviço público. ${ }^{17}$

Ou seja, ao contrário do modelo administrativo colonial britânico, que soube conceder um semblante de poder real às chefias locais por meio do

15 MAMDANI, Mahamood. Citizen and subject.

16 SURET-CANALE. Jean, L'Afrique Noire, p.94

17 "Despotism and total control were thus most evident at the level of the territoire, generally a vast area comprising several traditional chiefdoms. Here, the administrator was virtually in charge of everything, including the essential 
sistema de indirect rule, constituindo alianças com elites locais, delegando poderes locais à chefias tradicionais ou impostas, e fazendo disto um instrumento sistêmico de gestão dos assuntos locais, no modelo francês, salvo raras e breves exceções, ${ }^{18}$ isto não se deu. Pelo contrário, o sistema colonial francês destituiu e destruiu tudo que tivesse alguma ascendência política tradicional africana suscetível de servir de foco aglutinador de contestação e rebelião; combateu e deportou todos os soberanos que a ele se opusessem, e os exilou noutros territórios coloniais: foi o caso de Samori Touré, imperador de Segú, deportado no Gabão; do rei Gbehanzin do Dahomey, exilado nas Antilhas francesas etc.

Do mesmo modo, sistemas educativos e de saber genuinamente africanos foram suprimidos. Foi o caso, por exemplo, do sistema de escrita do reino Bamoun (situado no território atual dos Camarões), que tinha já dado lugar à escolarização local antes da invasão europeia: foi suprimido, e substituído pelo sistema educativo francês, lá onde até os alemães, primeiros colonizadores dos Camarões, tinham aceitado deixar funcionar este sistema educativo e de escrita genuinamente de invenção local. ${ }^{19} \mathrm{De}$ fato, na visão colonial francesa, nada deveria fazer concorrência e sombra à "missão civilizadora" da França, e seu "assimilacionismo" cultural.

Por outro lado, e de modo significativo, o caráter militarista do sistema francês perdurou praticamente até ao fim do império colonial; e quando a era dos governadores militares foi substituída pela geração de administradores civis, esses últimos acabaram por inserir-se, e perpetuar, na realidade, um sistema militarista no espírito e na prática. Suret-Canale caracteriza com efeito a administração colonial francesa como sendo de tipo marcial:

Do despotismo militar, a administração civil (colonial) preservou as formas exteriores e o vocabulário (...) 'mando', uniformes pomposos, saudação militar exigida aos 'administrados'. O comandante civil conserva, aliás, poderes militares ou policiais: lá onde já não tem soldados à sua disposição, ele tem as milícias indígenas, que seriam chamados de 'guardas-círculos' na AOF (África Ocidental Francesa). ${ }^{20}$

A coisa não se limitou, porém, ao simples uso das formas exteriores, uniformes pomposos e vocabulário de tipo castrense, numa espécie de

tasks of record keeping, order maintenance, tax collection, labour recruitment, conscription, the administration of justice and public service"; NZONGOLA-NTALANJA, Georges. The Congo from Leopold to Kabila, p.36-37.

18 Tratou-se nomeadamente da aceitação pela França da preservação de um certo poder local concedido às estruturas políticas tradicionais oriundas das realezas Mossi, no atual país Burkina Faso. SURET-CANALE. Jean. L'Afrique Noire.

19 Ver TÉNO, Jean-Marie. Afrique, je te plumerai. Camarões/França/Alemanha: Les Films du Raphia, Raphia Films Productions, Zweites Deutsches Fernsehen (ZDF), 1993. Disponível em: <http://.newsreel.org/nav/title. asp?tc $=$ cn0003 $>$. Acesso em: 22 jun. 2013. Téno é realizador e documentarista camaronês. O documentário trata dos efeitos devastadores e do legado cultural nocivo da colonização e do neocolonialismo sobre as sociedades africanas.

20 "Du despotisme militaire, l'administration civile (coloniale) a gardé les formes extérieures et le vocabulaire (...) 'commandement', uniformes chamarrées, salut militaire exigé des 'administrés.' Le commandant civil conserve 
"teatralização do poder", ${ }^{21}$ nomeadamente do poder imperial europeu face aos povos doravante assujeitados: a prática acabou conferindo um conteúdo militarizado e militarista ao sistema laboral, nomeadamente ao sistema de recrutamento, e de justificativa institucional, a nível local, da crueldade do sistema de trabalho forçado. E se o sistema perdurou, foi tanto pela missão que se conferia às colônias (geradoras de riquezas em beneficio das empresas e dos estados metropolitanos) como pela dinâmica econômica local, que acabaria conferindo às empresas privadas, às companhias concessionárias, um poder de manobra que desafiava, objetivamente falando, o controle que o Estado francês teoricamente exercia sobre o destino das colônias. Os abusos deste sistema depredador no caso do Congo francês, escreveu Catherine Coquery-Vidrovitch, teriam sido encorajados "pela impunidade do monopólio" de exploração econômica detida pelas companhias concessionárias:

O peso das (companhias) concessionárias manteve-se importante até ao fim: nenhuma reforma (legislativa) conseguiu pôr fim aos seus privilégios, cujo país (o Congo) ainda conserva os traços pois mais de um milhão de hectares foram finalmente abandonados às antigas sociedades..$^{22}$

Interessa analisar como se situavam as instituições metropolitanas face à questão do trabalho forçado.

\section{O Estado e a questão do trabalho coercitivo nas colônias fran- cesas: as ambiguidades}

No fundo, as ambiguidades, senão a aparente impotência do Estado francês face às companhias concessionárias desde o fim do século XIX, e até ao fim do regime de trabalho forçado (1947), correspondia às ambiguidades, ou mesmo às incertezas que marcaram o próprio projeto colonial francês, mormente na África Equatorial. No caso do conjunto de territórios da bacia do Congo "descobertos" pelo 'explorador' Pierre Savorgnan de Brazza, ao serviço e em nome da França, o Estado francês hesitou, e levou tempo antes de se decidir sobre o que faria dessa nova posse territorial.

O debate sobre esta matéria era, no fundo, o de se saber se o Estado francês devia gastar capitais para investir na exploração econômica desses territórios, e qual seria a viabilidade de tal empreendimento. A solução foi decidida em 1890, praticamente dez anos após o ato de "descoberta" de De Brazza: o Estado francês decidira finalmente

d'ailleurs des pouvoirs militaires ou de police: là où il n'a plus de soldats à sa disposition, il a les milices indigènes qui deviendront en AOF (Afrique Occidentale Française ) les 'gardes cercle'"; SURET-CANALE. Jean, L'Afrique Noire, p.95.

$21 \mathrm{COHN}$, Bernard S. Colonialism and its forms of knowledge: the British in India. Princeton: New Jersey: Princeton University Press, 1996, p.3.

22 COQUERY-VIDROVITCH, Catherine. Le Congo au temps des grandes compagnies concessionnaires, p.15. 
partilhar a colônia - que correspondia mais ou menos aos atuais territórios das repúblicas gabonesa, congolesa e centro-africana - entre 40 enormes concessões territoriais, totalizando cerca de $700.000 \mathrm{~km}^{2}$ sobre os cerca de 900.000 do conjunto. ${ }^{23}$

A essas empresas foram dadas vantagens fiscais, uma total liberdade, um monopólio de exploração dos recursos naturais, desde que fossem assegurados os $15 \%$ de benefícios ao Estado francês, num contrato que deveria durar trinta anos. Um sistema reminiscente, senão mesmo copiado do sistema 'leopoldino' em vigor no outro lado do rio Congo. ${ }^{24}$

Tratou-se, de fato de uma autêntica demissão do Estado: renunciando em fazer ele próprio os investimentos necessários, este esperava que a iniciativa privada, sob o aguilhão dos benefícios esperados, levaria, por si só, à valorização econômica do país. ${ }^{25}$

Face aos problemas que se colocam à exploração econômica da África Equatorial francesa, concretamente do "Congo francês", o uso coercitivo da mão de obra indígena aparece na visão colonial como única alternativa. Chegou-se mesmo, em alguns meios oficiais parisienses, a lamentar que o sistema escravagista tivesse sido abolido, pois "o negro não estava preparado para saborear os benefícios da liberdade", consoante afirma relatório escrito por um alto funcionário francês, M. Bérard, em 1899. ${ }^{26}$ Uma afirmação que legitimava o uso do trabalho forçado.

O recurso à mão de obra indígena, e a dependência do Estado francês em relação as companhias concessionárias como agentes na exploração econômica das colônias, desembocaram, logicamente, no uso de métodos de trabalho forçado, como temos vindo a referir. O Estado francês mal poderia ter controle sobre a realidade laboral no terreno, e muito menos combater legislativamente os abusos, quando assim o entendesse, apesar de envio de inspetores de trabalho, cujos relatórios de todo modo ora eram mal entendidos por políticos parisienses que não tinham a mínima ideia da realidade no terreno, ou ignorados, ${ }^{27}$ ora embatiam contra lobbies comerciais no seio das instituições republicanas francesas. De resto, em defesa do sistema que tinham apesar de tudo instituído, elaborou-se em Paris um discurso justificativo de práticas que a própria legislação republicana não aceitava. Aliás, esta não dizia respeito às colônias, geridas por leis próprias. A questão do "interesse nacional" passou a ser invocada.

23 COQUERY-VIDROVITCH, Catherine. Le Congo au temps des grandes compagnies concessionnaires, p. 27

24 NZONGOLA-NTALANJA, Georges. The Congo from Leopold to Kabila, p.26-27.

25 COQUERY-VIDROVITCH, Catherine. Le Congo au temps des grandes compagnies concessionnaires, p.25-26.

26 BÉRAUD, Médard. L'agriculture et la colonisation du Congo français: la main-d'œuvre. Paris: Impr. Chaix, 1899.

27 COOPER, Fredrick. Decolonization and African society. 
Com efeito, face às críticas levantadas a nível das instituições internacionais, nomeadamente da Organização Internacional do Trabalho (OIT), sobre o trabalho forçado nas colônias, e seus horrores, o governo francês iria constantemente justificar os métodos de arrebanhamento forçado de trabalhadores pelas empresas privadas nas colônias como fazendo parte do sistema de conscrição militar, ou seja, como sendo para o alto interesse da defesa nacional. ${ }^{28} \mathrm{E}$ na prática, tanto se usou este método para se recrutar tropeiros e milícias coloniais, quanto para se conseguir a mão de obra civil. O sistema acabaria de resto por adquirir uma espécie de vida e dinâmica próprias, que escapariam de certo modo à racionalidade administrativa, ou mesmo aos escrúpulos moralistas de oficias do governo central francês, desejosos de dar mais flexibilidade à coercitividade do sistema laboral. ${ }^{29} \mathrm{O}$ uso do trunfo castrense como justificativo de recrutamento forçado iria de certo modo reconciliar a avidez e o sem-escrúpulo das empresas privadas e companhias concessionárias, e os interesses do próprio Estado metropolitano. Às vezes, da mesma leva de arrebanhados para o trabalho forçado, uma parte ia para as companhias concessionárias, as empresas privadas europeias, enquanto que a outra parte era encaminhada para a conscrição militar, para o serviço do aparelho repressivo das milícias coloniais, e para os campos de batalhas africanos e europeus durante as duas guerras mundiais.

A OIT bem que podia, em vão, procurar, a partir de salas de conferências ou dos seus escritórios confortáveis em Genebra, distinguir uma coisa da outra. O contexto das duas guerras mundiais iria de certo modo conferir uma "legitimidade" a tal prática, que nem a OIT, e muito menos ninguém na metrópole colonial pensava contestar nesta "conjuntura especial" ${ }^{30}$ que foram os dois conflitos mundiais do século XX, em que se encontravam mergulhadas as potências colonizadoras e com elas (embora involuntariamente) os territórios colonizados. Sob tal justificativa conjuntural, os africanos iriam pagar não apenas pelo seu sangue como soldados, como também com um preço ainda mais alto a nível laboral com a mobilização econômica para o effort de guerre (esforço de guerra) de cada império colonial - um contexto que faria os africanos viverem "um verdadeiro pesadelo", ${ }^{31}$ onde a fome e a morte por maus tratos imperavam. A requisição de homens válidos para a produção dedicada ao effort de guerre deixou aldeias inteiras sem força produtiva para a economia local, e os que estavam adstritos aos diversos ramos da economia que deviam ajudar a colônia no seu effort de guerre, estavam subjugados, mais uma vez, como no século XIX, a condições de trabalho nada muito diferente do trabalho escravo.

28 COOPER, Fredrick. Decolonization and African society.

29 COOPER, Fredrick. Decolonization and African society.

30 POULANTZAS, Nicos. Pouvoir politique et classes sociales. Paris: Éditions Maspéro, 1968.

31 COOPER, Fredrick. Decolonization and African society, p.110. 
Mas antes de tudo, o assento físico deste processo para todos os sistemas coloniais, o ponto de partida na estruturação do sistema de violência e o ato-mor de mise en pratique da colonização, ou seja, o primeiro ato de possessão/valorização econômica das colônias foi, sem dúvida alguma, a expropriação da terra do colonizado.

\section{A expropriação da terra como matriz do sistema de violência}

O vício do sistema começou pela ocupação da base física da economia, outrora pertença comum das populações conquistadas: a terra. Sua expropriação tinha um duplo fundamento. Por um lado, ela deixava os nativos economicamente dependentes, sem direito à exploração e uso por conta própria da sua maior riqueza material - a base secular da sua sobrevivência simbólica identitária substanciada por uma forte ligação aos rios e florestas, relevo, fauna e flora. Um bem que era a base de mitos e lendas ligados ao seu uso, à sua posse comum ou familiar, gerações após gerações. Por outro lado, e consequentemente, essa expropriação colocava as comunidades economicamente e identitariamente ao dispor das companhias concessionárias ou indústrias mineiras, como mão de obra barata, senão semiescrava. A título de exemplo, as expropriações das terras Kikuyu no Quênia a favor dos colonos britânicos, as expropriações das terras Kongo no norte de Angola, ou no "Estado Livre do Congo", e no Congo 'francês', a favor das companhias concessionárias, e também o famigerado Land Act de 1913, na África do Sul em pleno boom da economia mineira daquele país. Todos estes exemplos participavam deste processo de mise en dépendance, além da perda de rumo que se apoderara de repente da vida de quem, um belo dia, acordaria sem terra.

"Despertando numa manhã de Sexta Feira, de 20 de Junho de 1913, o nativo sul-africano descobriu que se tinha tornado, não escravo, mas pária na sua terra natal", escreveria por exemplo, em 1916, o jornalista e dramaturgo sul-africano Sol Plaatje, a seguir o Land Act de 1913, que retirava aos negros sul-africanos a posse da terra. ${ }^{32}$ Desta forma, o maior, ou se quisermos, a "mãe" de todos os roubos materiais - a expropriação da terra aos nativos - deixava de ser

um simples roubo de recursos dos povos, para se transformar em uma parte quotidiana do processo de trabalho. (Ele) já não constituía uma expropriação, mas sim, uma apropriação sistemática. ${ }^{33}$

32 "Awaking on Friday morning, June 20, 1913 the South African native found himself, not actually a slave, but a pariah in the land of his birth". PLAATJE, Sol. Native life in South Africa. London: Harlow, 1987, p.16.

33 FREUND, Bill. The making of Contemporary Africa: the development of African society since 1800. 2 ed. Boulder, CO: Lynne Rienner Publishers, Inc., 1998, p.98 (Sublinhado pelo autor). 
Nisto, o sistema concessionário leopoldino (isto é, instituído pelo rei belga Leopold II), no "Estado Livre do Congo", foi, como já vimos, mestre e gerador das piores atrocidades coloniais imagináveis; foi também o caso do sistema britânico na África Oriental, sem falar das imensas expropriações portuguesas em Angola, mormente a seguir a II Guerra Mundial, ${ }^{34} \mathrm{e}$ suas consequências demográficas com as migrações e deslocações de populações que se seguiram.

Sobre a questão da posse da terra, no caso da África Equatorial Francesa, Coquery-Vidrovitch mostra como o debate sobre a questão da propriedade da terra acabou assumindo contornos malignos, cuja base seria o princípio de que as terras eram "livres e sem donos" pois "não utilizadas pelas 'tribos' locais". ${ }^{35} \mathrm{O}$ fato de existirem terras comunitárias, cujo uso era devidamente organizado sob supervisão de chefes tradicionais locais ("chefes de terra"), não demoveu os argumentos baseados em ideias como "terras não cultivadas" (portanto "sem donos"), ou "mobilidade das comunidades nativas". Dessas expropriações legalmente sancionadas pelo poder público (o Estado francês) e dos lucros que elas geravam, nasceria um conjunto de privilégios de que iriam gozar as companhias concessionárias. Distingue-se a atribuição de monopólios para a exploração de todas as riquezas naturais, sendo este o ponto de partida para a extração do trabalho coercitivo que iria devastar as comunidades nativas nesta região: "Na prática, as (companhias) concessionárias apropriaram-se das riquezas naturais". ${ }^{36}$

Esse processo de expropriação da terra lançava de fato as bases materiais e estruturais para o processo econômico colonial, a condição-mor da implementação do projeto colonial, e a justificação sistêmica da violência como parte desse processo econômico. Pelo que importa examinar a economia politica desta violência sistêmica.

\section{A economia política da violência colonial: as raízes sistêmicas da coerção laboral}

Os motivos da estruturação do sistema de violência "legal", tal como resumido acima, tem portanto a ver com a organização e estruturação da economia colonial, da necessidade da maximização do seu rendimento. Falando do funcionamento do sistema colonial erguido no Congo pelos franceses, Catherine Coquery-Vidrovitch escreve por exemplo:

O sistema colonial (francês no Congo) resultou diretamente da penúria em meios investidos. Para paliar os crônicos males do país - a ausência de infraestruturas

34 BENDER, Gerald J. Angola under the Portuguese: the myth and the reality. London: Heinemann, 1978.

35 COQUERY-VIDROVITCH, Catherine. Le Congo au temps des grandes compagnies concessionnaires, p.224-225.

36 COQUERY-VIDROVITCH, Catherine. Le Congo au temps des grandes compagnies concessionnaires, p.225. 
e de pessoal, resultado da penúria de capitais, e a falta de mão-de-obra derivada de um subpovoamento acentuado - recorreu-se a procedimentos autoritários. Por falta de meios e braços, o edifício repousara sobre o constrangimento erguido em princípio de colonização. ${ }^{37}$

Ou seja, na ausência de créditos e meios financeiros que permitissem uma exploração dos territórios conquistados, o sistema colonial teve de instituir práticas meio-escravistas para poder implementar cabalmente a exploração econômica, ou mise en valeur das colônias. Desta forma, a violência acabou se instalando como um todo sistêmico, e não como uma prática gratuita per si, e sem conexão com o processo econômico colonial. Que o colono tenha construído um discurso baseado em categorias tais como a "preguiça natural dos negros", sua "recusa do trabalho civilizado", e, por conseguinte, o dever do colonizador de combater tal "preguiça" pela violência ("o negro só compreende as coisas com o chicote"): tudo isto pertenceu ao discurso ideológico colonial, que não se justificaria per si, se não o ligássemos ao processo econômico justificativo do fato colonial.

Mas como vimos, do administrador colonial ao kapita/capataz, passando pelos lobistas recrutadores de mão de obra ao serviço das companhias privadas, o excesso de zelo participava também, a título individual, de um interesse compensatório e estatutário para uns, a uma sobrevivência estatutária e física para outros. Isto justifica a dificuldade que houve de implementar reformas legislativas decretadas pelos governos metropolitanos: a realidade do processo de exploração econômica no terreno tornaria os lobistas e funcionários das companhias em potentados locais, que tinham mão no dia-a-dia colonial, ao contrário dos funcionários das administrações centrais, longe da realidade colonial cujo conhecimento Ihes provinha através dos relatórios dos governadores, ou inspetores coloniais. ${ }^{38}$ Assim, torna-se impossível separar colonização/processo econômico colonial e violência laboral.

O trabalho forçado acabava por simbolizar a violência de um sistema de exploração capitalista que, naquela fase do fim do século XIX e nas primeiras décadas do século XX, até pelo menos ao fim da II Guerra Mundial, estava na sua transição da fase mais brutal, ainda prenhe de herança do trabalho escravista, para um capitalismo mais moderno. Isto colocou constantemente o discurso moralista e antiescravista europeu, construído no século XIX, perante impossíveis dilemas e inúmeras contradições. De resto, esse mesmo moralismo do humanismo europeu não tinha cabalmente confrontado a realidade dos fatos coloniais. O próprio movimento abolicionista, no qual os discursos filantrópicos antiescravistas, britânicos

37 COQUERY-VIDROVITCH, Catherine. Le Congo au temps des grandes compagnies concessionnaires, p.15. 38 COOPER, Fredrick. Decolonization and African society. 
ou franceses, nem sempre correspondiam à prática ou à realidade das exigências econômicas do momento.

Estas realidades eram de carácter global com a permanência, até quase aos finais do século XIX, de uma economia de plantações nas ilhas caribenhas sob o domínio europeu. No Brasil, fazia-se vista grossa face à perpetuação clandestina, por décadas ainda, do tráfico negreiro. A multiplicidade dos casos levou a que a Inglaterra tomasse decisões pelo menos parcelares de policiamento antiescravagista dos oceanos: um policiamento por assim dizer de duas faces, que olhava para uma parte das costas africanas (a norte do Equador), e deixava a outra parte tão porosa que os navios portugueses e outros podiam continuar transportando clandestinamente a sua mercadoria humana para as Antilhas e o continente sul-americano até o final do terceiro quarto do século XIX. Ao mesmo tempo que as naus da marinha da Sua Majestade patrulhavam o Atlântico, empresas, assim como diplomatas britânicos no Brasil, continuavam a recorrer ao trabalho escravo. ${ }^{39}$

Uma duplicidade que se ilustrava também no fato da Inglaterra continuar a importar o açúcar produzido em $\mathrm{Cuba},{ }^{40}$ onde as plantações de canade-açúcar ainda se alimentavam deste tráfico atlântico clandestino nessa mesma época, até os anos 1880, num fluxo contínuo que nem o policiamento dos oceanos conseguia desencorajar. ${ }^{41} \mathrm{E}$ disto nem os britânicos, nem os franceses, nem os espanhóis no caso de Cuba, e muito menos ainda os portugueses (depois do decreto de 10 de Dezembro de 1836 até à Lei de 1875), ${ }^{42}$ saíram 'limpinhos' desta contradição entre decretos e discursos abolicionistas por um lado, e a realidade duradoura da perpetuação ainda por décadas, do dito comércio por outro lado. Suas práticas logo no início do processo colonial, iriam de resto desembocar em escândalos denunciados como práticas escravagistas por organizações humanitárias e missionários europeus e americanos desde os finais do século XIX:

Também a França como a Grã-Bretanha elas próprias tiveram que fazer face as críticas por parte dos puristas do mercado do trabalho. Essas críticas usavam frequentemente o termo "escravatura" - e a imagem da morte e da desumanização fazia eco àquelas usadas pela propaganda antiescravista - para dramatizar políticas que tinham ultrapassado os limites. Uma larga publicidade foi dada aos escândalos do trabalho forçado ocorridos no Quênia, em 1919, e na África Equatorial Francesa nos anos 1920. Todos os regimes defendiam-se invocando

39 CONRAD, Robert. The destruction of Brazilian slavery, 1850-1888. Berkelye/Los Angles/London: University of California Press, 1972, p.14

40 THOMAS, Hugh. The slave trad: the story of the Atlantic slave trade, 1440-1870. New York: Simon \& Schuster, 1997, p.769-785.

41 SCOTT, Rebecca J. Slave emancipation in Cuba: transition to free labor, 1860-1899. Pittsburgh: University Press of Pittsburgh, 2000, p.3-7.

42 Decreto que, na realidade, exprimia a intenção de se abolir o tráfico atlântico por Portugal, mas ainda não da escravidão em si, a qual imperrou nas colônias africanas até 1875. Para os debates sobre esta questão em Portugal no século XIX, ver MARQUES, João Pedro. Sá da Bandeira e o fim da escravidão: vitória moral, desforra do interesse. Lisboa: Imprensa de Ciências Sociais, 2008. 
o interesse público, acima de tudo a necessidade de se desenvolver a rede de transporte com vista a "abrir" África, e para se justificar o uso provisório do trabalho forçado. ${ }^{43}$

No caso francês, tal violência laboral iria desembocar em muitas rebeliões, cuja mais importante e mais estruturada militarmente foi a rebelião levada a cabo pelos povos Banda, Foulbé e Gbaya, ${ }^{44}$ mais conhecida e ainda retida pela memória coletiva dessa região (compreendida entre o sul dos Camarões e do Tchad, oeste da República centro-africana) sob o nome genérico de "guerra de Kongo-wara", ${ }^{45}$ um vasto movimento de rebelião que se alastrou de 1928 a 1932, e iria afetar o sistema concessionário e colonial em geral na África Equatorial Francesa. ${ }^{46}$ Esta rebelião constituiu "a mais importante das insurreições anticoloniais na África negra, então sob o domínio francês", escreve Suret-Canale. ${ }^{47}$

Esta série de rebeliões mostrava duas coisas: por um lado que a liberdade dada às companhias concessionárias de disporem das terras e das populações, tanto no Congo belga como na África Equatorial francesa, desembocara em horrores sem nome no uso do trabalho coercitivo. Por outro lado, esses horrores, por si mesmos, traduziam a dependência econômica dos estados colonizadores das companhias concessionárias; ou seja, o empreendimento privado e os seus lobbies detinham um grande peso econômico que por sua vez engrandeciam a sua força política. E são esses lobbies que iriam gerir a prática laboral no recrutamento da mão de obra, e que acabariam inclusive desafiando e driblando no terreno qualquer avanço legislativo positivo do Estado metropolitano sobre a questão do trabalho forçado nas colônias. ${ }^{48}$ No caso da África Equatorial francesa, e mais precisamente do Congo, escreve Catherine Coquery-Vidrovitch,

43 "France and Britain themselves faced criticism from the purists of the labor market. The critics frequently used the word "slavery" - and image of death and dehumanization echoing those of anti-slavery propaganda - to dramatize policies that stayed beyond the bounds. Wide publicity was given to forced labor scandals in Kenya in 1919 and in French Equatorial Africa in the 1920s. All regimes defended themselves by evoking public purpose, above all the need to develop transportation network to "open" Africa, to justify the provisional use of forced labor"; COOPER, Fredrick. Decolonization and African society, p.27.

44 COQUERY-VIDROVITCH, Catherine. Le Congo au temps des grandes compagnies concessionnaires, p.15.

45 A guerra de Kongo-Wara (ou "guerra de enxada") foi uma rebelião anticolonial com características messiânicas, liderada por Karnou. Este fez da enxada seu símbolo de luta, e exortava os seus adeptos e combatentes supostamente com as seguintes palavras, tais como retranscritas em língua francesa nos arquivos coloniais: "Matais, comeis vosso gado, repudiais vossas esposas, queimeis vossas casas, corteis as pontes, tudo que tenha tido contacto com o Branco é impuro e deve desaparecer (...) Tomeis meu medicamento, o Kougowara e eu estarei ao lado de quem quer que o tenha pendurado ao seu pescoço, e tornar-lhe-ei invisível e invulnerável". Tradução minha. Ver: DUBOIS, Colette. Le prix d'une guerre: deux colonies pendant la Première Guerre Mondiale (Gabon Oubangui-Chari) (1911-1923). Thèse de doctorat 3ème cycle d'histoire. Université de Provence, Aix-en-Provence, Institut d'Histoire des Pays d'Outre-Mer, 1986, p.449-345. Section II, 2ème Partie, Chapitre I, p.166.

46 Ver nomeadamente a magistral, e até ao momento única obra de vulto consagrada à esta rebelião pelo falecido historiador centro-africano NZABAKOMADA-YAKOMA, Raphaël. L'Afrique centrale insurgée: la Guerre de KongoWara (1928-1930). Paris: L'Harmattan, 1986. Ver igualmente BURNHAM, Ph.; CHRISTENSEN, T. Karnu message and the 'War of the Hoe Handle': interpreting a central African resistance movement. Africa, Londres, v.III, n.1, p. 3-21, 1983; CHRISTENSEN, T. Karnu, Witchdoctor or Prophet?. Missiology, Chicago, v.6, p.197-211, 1978.

47 SURET-CANALE, Jean. Preface. In: NZABAKOMADA-YAKOMA, Raphaël. L'Afrique centrale insurgée, p.7.

48 COOPER, Fredrick. Decolonization and African society. 
por falta de meios e de mão de obra, o edifício do sistema de exploração econômica "repousou sobre o constrangimento erguido em princípio de colonização". ${ }^{49}$

De resto, a legislação em uso nas colônias estava sistematicamente em contradição com, por um lado, os progressos legislativos registrados em benefício do mundo do trabalho metropolitano, e, por outro lado, a negação da sua aplicação nas colônias. As mudanças "positivas" no caso colonial encontravam constantes bloqueios pelos funcionários coloniais e lobistas empresariais, assentes na ideia de que os africanos nem iriam compreender tais leis, pois estavam alheias à sua mentalidade "tribal": a ideologia do discurso colonial iria fazer disto, e do argumento da "preguiça nata dos negros", um dos fundamentos da sua teleologia do fato colonial, e do sistema laboral, tal como implementado nas colônias:

O argumento de que o negro precisava de forte supervisão de um estado civilizado antes de poder embarcar no "curso natural" da racionalidade do mercado ajudou os poderes europeus a conceberem-se a eles próprios como imperialistas progressistas na conquista de África no fim do século XIX. A África vista como um continente onde reinava a escravatura - oprimido e mantido fora do caminho da civilização, do Cristianismo e do comércio pelos seus próprios tiranos - foi a imagem central da propaganda missionária, e mais tarde a base fundamental do argumento imperialista.50

Afora discursos oficiais sobre a pretensa "missão civilizadora" europeia, a realidade do lugar do colonizado nesta "missão" era outra, face ao fim último de todo empreendimento colonial, e ao lugar do colonizado nele: "O homem interessa à colonização apenas como força de trabalho", escreve Jean Suret-Canale. ${ }^{51}$

Este fato indiscutível levanta, aliás, a questão da substância das diferenças entre os diversos sistemas coloniais, nomeadamente entre os dois principais - 'direct rule' versus 'indirect rule', ou seja sistema colonial de "tipo" francês contra o sistema colonial de "tipo" britânico. Que diferença fazia isto, na prática, na questão laboral nas colônias, e face à violência que, como vimos, tanto foi usada pelos britânicos como pelos franceses e outros?

49 COQUERY-VIDROVITCH, Catherine. Le Congo au temps des grandes compagnies concessionnaires, p.15.

50 "The argument that blacks needed the stern supervision of civilized state before they could embark on the "natural course" of market rationality helped European powers to acquire a sense of themselves as progressive imperialists in the course of the late nineteenth-century conquest of Africa. Africa as a slave-ridden continent - oppressed and kept off the path to civilization, Christianity, and commerce by its own tyrants - became the central image of missionary propaganda and later a key basis of pro-imperialist argument"; COOPER, Fredrick. Decolonization and African society, p.25.

51 "L'homme n'intéresse la colonisation que comme force de travail"; SURET-CANALE, Jean. Préface. In: NZABAKOMADA-YAKOMA, Raphaël. L'Afrique centrale insurgée, p.10. 


\section{"Direct rule", "indirect rule": farinha do mesmo saco na questão laboral?}

A questão fundamental era como fazer as colônias "renderem" e "desingurgitarem" ao máximo as suas riquezas naturais; como fazer o colonizado produzir mais, e como levá-lo a aceitar, bem ou mal, voluntariamente ou à força, o sistema laboral trazido pela economia capitalista. Como integrar o colonizado neste sistema cheio de uma violência que não correspondia nem simbolicamente, nem na prática, aos seus valores? Como assentar o domínio cultural e psicológico do conquistador? Como redesenhar, em conformidade e paralelamente, o mundo cultural e espiritual do sujeito colonial usando as "tecnologias culturais" adaptadas, através dos "saberes" elaborados por aqueles a quem Aimé Césaire chamaria ironicamente, usando um neologismo pejorativo de sua invenção, de ethnographes dogoneux ${ }^{52}$ (etnógrafos 'dogonosos' - em referência aos etnólogos franceses pretensamente 'especialistas' do povo Dogon do Mali, e que usavam de um discurso eurocêntrico e na sua tentativa de "restituir" a realidade intrínseca deste povo das montanhas sahelianas). Enfim, uma lista, de resto infinita, de perguntas que induziam e implicavam a questão do lugar imposto aos donos da terra neste múltiplo processo de estruturação econômico-administrativa e cultural dos territórios conquistados. Cujos donos, obviamente, não estavam nada dispostos, em termos globais, a ceder aquilo que Ihes pertencia desde tempos imemoriais, por um lado; por outro lado, não estavam nada inclinados em obedecer ao tipo de sistema laboral que lhes era imposto tanto pelo conteúdo como pela forma: um sistema estruturado no modo capitalista de rendimento absoluto, com toda a sua violência tanto estrutural como cultural e simbólica. Mesmo que o sistema colonial inglês tenha feito algum uso mais "ajuizado" na forma como instrumentalizou as estruturas pré-coloniais que encontrou nos territórios conquistados, a verdade é que ele também recorreu à prática própria de todo o sistema colonial. Ou seja, o sistema colonial inglês também usou a violência e o trabalho forçado como instrumento de produção e de produtividade; fez alianças com as autoridades tradicionais locais para servir seus interesses, e desestruturou e reconstituiu instituições locais conforme achava necessário e útil para o processo econômico. Assim sendo, também combateu, humilhou, deportou, encarcerou - ou matou quando fosse necessário - soberanos e chefes africanos que recusassem submeter-se à coroa britânica e usassem em sua defesa a resistência armada- como mostra o caso das guerras de ocupação ou de repressão de levantamentos anticoloniais na África ocidental, austral e oriental; esmerou no uso de campos de concentração lá onde fosse necessário, da África do Sul contra outros brancos, rebeldes,

52 CESAIRE, Aimé. Discours sur le colonialisme. Paris: Présence Africaine, 1955. 
durante a guerra anglo-boer de 1898-1902, ao Quênia durante a revolta dita dos Mau Mau, em 1952-1956. ${ }^{53}$

No plano ideológico, o indirect rule não impediu, de forma alguma, que o imperialismo britânico procurasse sustentar e assentar o rendimento econômico das colônias na base ideológica correspondente. Para este fim, os britânicos fizeram uso dos seus etnólogos ou os doravante especialistas de "povos primitivos" para reconstruir e transformar formas culturais antigas das sociedades conquistadas de forma a instaurar as categorias que iriam separar o mundo "superior" ocidental do mundo "atrasado" do colonizado. Ou seja, como sublinha Dirks no caso da Índia, implementaram o sistema de dominação usando categorias sistêmicas: "a oposição entre colonizadores e colonizados, Europeu e Asiático, moderno e tradicional, Ocidente e Oriente". ${ }^{54}$

Do mesmo modo, e nessa mesma senda, o colonialismo britânico procedeu, como outros, à criação de núcleos de elites africanas para servirem de auxiliares do sistema, com o fim de "desempenharem funções de execução econômica". ${ }^{55}$ Pois a questão da categorização cultural e da distinção estrutural entre colonizador e colonizado, "civilizado" e "incivilizado/ selvagem", nação (entende-se para os europeus) e "tribo" (termo aplicado aos africanos), europeu e não-europeu, branco e negro, participava da estruturação e da justificação da economia e sua violência intrínseca.

Desse modo, a questão cultural, e as classificações raciais elaboradas com a ajuda dos "etnógrafos dogonosos" do sistema colonial, participavam da obra de mise en condition do colonizado, com vista a consolidar a obra de conquista e exploração econômica. Sendo assim, não se pode analisar de forma separada a violência econômica e a violenta desestruturação cultural levada a cabo pelo processo colonial, assim como o racismo que se institui como peça fundamental deste sistema de opressão. Trata-se de uma necessidade intrínseca, sem a qual não se entenderia nem se justificaria o processo colonial: o colonizador sabe que a violência que semeia através do processo econômico gerará, mais cedo ou mais tarde, ódio, e deverá mais cedo ou mais tarde provocar contra-violência. ${ }^{56} \mathrm{~A}$ obra de desestruturação e negação cultural e de condicionamento ideológico se torna uma necessidade absoluta e vital para a sobrevivência do sistema:

No contexto do colonialismo como estrutura de dominação, esta negação é uma "necessidade" inerente ao sistema colonial. É uma necessidade porque a cultura indígena é um meio poderoso de resistência contra o colonialismo. ${ }^{57}$

53 ELKINS, Caroline. Imperial reckoning: the untold story of Britain's gulag in Kenya. New York: Henry Holt and Company, 2005.

54 DIRKS, Nicholas; B. Forword. In: COHN, Bernard S. Colonialism and its forms of knowledge, p.IX.

55 BÉNOT, Yves. Idéologies des Indépendances africaines. Paris: Maspero, 1972, p.66.

56 FANON, Frantz. Les damnés de la terre. Paris: La Découverte, 2002

57 "In the context of colonialism as a structure of domination, this negation is a 'necessity inherent in the colonial system'. It is a necessity because indigenous culture is a potent means of resistance against colonialismo"; NZONGOLA-NTALANJA, Georges. The Congo from Leopold to Kabila, p.38. 
Quando os franceses aboliram o sistema de escrita do reino de Bamoun, e as estruturas educativas ligadas a este e montadas pelo rei Njoya I, estavam na lógica deste pensamento colonial - não fosse o soberano africano transformar um dia esta genuína invenção, e a estrutura educativa subsequente, num instrumento de resistência anti-francesa. Os mesmos franceses e seus historiadores e outros "etnógrafos dogonosos" iriam, no entanto, invocar a falta de escrita em muitas sociedades africanas para alimentar o seu discurso racista sobre o "atraso" dos negros, e a necessidade de os "civilizar".

Seja como for, a implementação de qualquer sistema colonial, fosse ele "direto" ou "indireto", obedecia antes de mais nada a um processo de desestruturação/estruturação do espaço econômico conquistado, e ao subsequente processo da sua administração e criação de infraestruturas destinadas à implementação do projeto colonial. ${ }^{58}$ Para tal, iria usar-se tudo que pudesse sustentar e reforçar, tanto por meio de "cultural technologies of rule"59 como por uma ideologia baseada numa teleologia adaptada aos fins visados, na imposição de um sistema que iria viver e reproduzir-se por meio da brutalidade como modus operandi. Brutalidade sem a qual não se entenderia o objetivo da colonização como processo histórico-econômico, resultante da expansão econômica europeia iniciada no século XV. O comportamento igual de todos os impérios coloniais na questão relacionada com o trabalho forçado é testemunha disto, tal como foi o pesadelo que fizeram viver os povos colonizados durante o tempo das duas guerras mundiais e a subsequente era do effort de guerre. Pelo que a violência, fosse ela mais mediada sob o mais "positivo aspecto" do indirect rule, ou mais direta, sob o direct rule, e fosse ela física ou psicológica, real ou simbólica, participava desta desestruturação/estruturação do espaço colonizado.

Desta forma, a violência estrutural colonial correspondia a esta dialética relacional entre colonizado e colonizador no processo do aproveitamento econômico - capitalista - das colônias, e seu enquadramento cultural e ideológico. Essa dialética relacional, e a sua tradução em violência estrutural, eram com efeito implementadas e expressas em função dos objetivos econômicos, das metas visadas, e das formas de as atingir, sob a pressão da demanda dos mercados das nações colonizadoras e da economiamundo capitalista.

No plano ideológico, não é possível levar cabalmente uma obra colonizadora sem lavagem cerebral nem condicionamento ideológico, e sem um trabalho de afirmação, por meios que variaram de sistema colonial para sistema colonial, mas que equivaliam em termos de filosofia de base, assente na ideia da superioridade civilizacional do colonizador. A estruturação

58 FREUND, Bill. The making of Contemporary Africa.

59 DIRKS, Nicholas; B. Forword. In: COHN, Bernard S. Colonialism and its forms of knowledge, p.IX. 
e a subsequente aplicação da violência multidimensional do fato colonial iriam inevitavelmente seguir e adaptar-se à evolução dos próprios sistemas coloniais. Isto iria dar-se essencialmente após a ll Guerra Mundial, mas em ritmos diferentes, e em função da evolução e pressões provindas dos territórios de cada império colonial. Nisto, o império colonial português seria o último a embarcar, sob pressão das lutas armadas anticoloniais iniciadas em 1961, no comboio de mudanças da legislação do trabalho - mas nem por isto, ou pelo menos não ao mesmo ritmo, no que dizia respeito à violência colonial como tal - nas suas colônias.

\section{A evolução do sistema laboral colonial francês: seus fundamentos}

No caso do sistema francês, importa sublinhá-lo, esta evolução foi primeiro marcada pela transição do domínio monopolístico das companhias concessionárias para um sistema econômico mais aberto, em que outros empreendimentos, nomeadamente ligados ao comércio livre, puderam ocupar maior espaço. ${ }^{60}$ Isto resultava de fato das controvérsias, e denúncias das atrocidades que, tanto o sistema leopoldino no "Estado livre do Congo", como as concessionárias da África Equatorial francesa, tinham cometido. Tal evolução significava um reordenamento do espaço econômico colonial, e subsequentemente das legislações que regulamentavam o sistema laboral neste espaço.

Esta evolução aconteceu em todos os impérios coloniais, embora em ritmos diferentes, consoante tanto as dinâmicas internas em cada colônia, como as resistências e evolução das legislações que geriam as colônias no seio do poder central metropolitano. Lá onde os britânicos e os franceses aceleraram as reformas a todos os níveis, inclusive político-legislativo, nomeadamente a seguir a II Guerra Mundial, os portugueses iriam obstruir toda ideia de se dar espaço político e social aos colonizados em todos os setores. Foi preciso a irrupção da violência armada anticolonial para que, finalmente, o poder salazarista aceitasse a ideia de remover o estatuto do indigenato em 1962, a seguir o eclodir das lutas armadas na África portuguesa a partir de 1961 (em Angola), e para que flexibilizasse as leis laborais que punham fim, oficialmente, ao trabalho forçado. ${ }^{61}$ Mas o colonialismo português continuaria resistindo a uma acomodação institucional e política dos colonizados, preferindo dar primazia à força militar - um terreno onde outros impérios coloniais tinham falhado ou desistido antes.

60 COQUERY-VIDROVITCH, Catherine. Le Congo au temps des grandes compagnies concessionnaires, p.233.

61 Ver entre outros: HENDERSON, Lawrence. A Igreja em Angola. Lisboa: Editorial Além-Mar, 1990; MESSIANT, Christine. 1961, L'Angola colonial, histoire et société: les prémisses du mouvement nationaliste. Bâle, Switzerland: P. Schelttwein Publishing, 2006. 
No caso francês, que nos concerne aqui, a evolução do sistema laboral e da sua violência estrutural seguiu a evolução da descentralização territorial global do império colonial. Ela marcou de fato uma espécie de braço-de-ferro entre as companhias concessionárias e o Estado francês cujo 'demissionismo', como vimos, permitiu o domínio quase que absoluto das concessionárias durante as primeiras décadas da ocupação colonial. A questão iria ser objeto de disputas políticas e de confrontos de interesses concessionários em Paris. Interessantemente, uma das vítimas desses confrontos de interesses iria ser o próprio Pierre Savorgnan de Brazza, o "descobridor" do Congo, cuja oposição ao reinado impiedoso das companhias concessionárias, assim como a sua denúncia das atrocidades por elas cometidas, ${ }^{62}$ iriam resultar na sua total marginalização em França, até a sua morte em Dakar, no Senegal, em 1905, em pleno auge do confronto de interesses no parlamento e no mundo econômico e político franceses sobre a questão colonial.

Seja como for, as mudanças mais significativas na gestão despótica das colônias apenas ocorreriam, fundamentalmente, após a II Guerra Mundial, e sob pressão tanto da emergência de movimentos emancipacionistas, como e sobretudo a partir das guerras de libertação na Indochina (19451954) e na Argélia (1954-1962), com alguma descentralização da estrutura administrativa, e abertura do espaço associativo e político aos nativos. As pressões exercidas pelos nacionalistas africanos levaram à adoção de uma nova legislação laboral, que punha fim ao trabalho forçado. Concomitantemente, maior espaço foi dado para uma participação dos africanos aos assuntos da colônia, e algumas mudanças na estrutura do império colonial. Tais mudanças, na verdade, tocavam apenas o essencial do topo da estrutura governativa das colônias. Elas justificavam-se, na realidade, no âmbito de um projeto de transformação da antigamente hipercentralizada estrutura do império colonial em uma federação, no quadro da 'União Francesa', que fora instaurada pela constituição de 1946 . $^{63}$

Pretensamente, tratava-se de uma nova estrutura de estado em que as colônias já não mais seriam colônias, mas sim territórios federados. $\mathrm{Na}$ prática, tal estrutura estatal não passava de "uma federação de inspiração colonial e desigualitária, no seio da qual a república francesa e as suas instituições jogariam um papel essencial, senão hegemônico". ${ }^{64}$ A França que saira da II Guerra Mundial aceitava abolir os piores aspectos da violência colonial, nomeadamente o trabalho forçado (abolido em 1947), mas recusava-se a introduzir reformas profundas, e muito menos a encarar a

62 COQUERY-VIDROVITCH, Catherine. Le Congo au temps des grandes compagnies concessionnaires.

63 GRIMAL, Henri. La décolonisation de 1919 à nos jours. Nouvelle édition. Paris: Editions Complexe, 1985

64 BOURGHI, Albert. Passé colonial et évolution des Etats d'Afrique noire francophone. In: COQUERY-VIDROVITCH, Catherine; FOREST, Alain. Décolonisation \& nouvelles dépendances: modèles et contre-modèles idéologiques et culturels dans le Tiers-Monde. Lille: Presse Universitaires de Lille, 1986, p.111-121. 
ideia de ter que preparar os territórios colonizados para uma independência total. Foi preciso a contra-violência nacionalista em algumas dessas colônias (Indochina em 1945-1954, Madagáscar em 1947, Argélia em 1954-1962, os Camarões em 1955, para citar apenas as mais violentas revoltas e rebeliões ou inícios de lutas armadas de libertação anticoloniais a seguir a II Guerra Mundial), e seus efeitos dominós nos restantes territórios coloniais, para que o sistema que tinha engendrado todas as violências (física, econômicas, culturais, espirituais etc.) pudesse acabar, com a descolonização. 


\section{ERRATA}

No artigo "Considerações sobre o despotismo colonial, e a gestão centralizada da violência no Império colonial francês", publicado no número 51, volume 29, da revista Varia Historia, na página 747:

Onde se lê:

"podemos concordar com Matamos Mamdani quanto ao fato"

Leia-se:

“(...) podemos concordar com Mahamood Mamdani quanto ao fato (...)"

No mesmo artigo, na página 759:

Onde se lê:

“(...) em 1916, o jornalista e dramaturgo sul-africano Sol Plante, (....)"

Leia-se:

“(...) em 1916, o jornalista e dramaturgo sul-africano Sol Plaatje, (....)"

No mesmo artigo, na página 761 :

Onde se lê:

"Isto colocou constantemente o discurso moralista e antiescravista europeu, construído no século XX"

\section{Leia-se:}

"Isto colocou constantemente o discurso moralista e antiescravista europeu, construído no século XIX"

No mesmo artigo, na página 763:

\section{Onde se lê:}

“(...) cuja mais importante e mais estruturada militarmente foi a rebelião levada a cabo pelos povos Badanai e Gbaya, mais conhecida e ainda retida pela memoria coletiva dessa região (compreendida entre o sul dos Camarões e do Tchã̃, o oeste da República centroafricana) (...)"

\section{Leia-se:}

“(...) cuja mais importante e mais estruturada militarmente foi a rebelião levada a cabo pelos povos Banda, Foulbé e Gbaya, mais conhecida e ainda retida pela memoria coletiva dessa região (compreendida entre o sul dos Camarões e do Tchã, o oeste da República centro-africana) (...)"

No mesmo artigo, na página 765 :

Onde se lê:

“(...) usando um neologismo pejorativo de sua invenção, de ethnologues dogoneux (etnólogos 'dogonosos' (...) 


\section{Leia-se:}

“(...) usando um neologismo pejorativo de sua invenção, de ethnographes dogoneux (etnógrafos 'dogonosos' (...)

No mesmo artigo, na página 766:

Onde se lê:

“(...) as classificações raciais elaboradas com a ajuda dos "etnólogos dogonosos" do sistema colonial (...)"

Leia-se:

“(...) as classificações raciais elaboradas com a ajuda dos "etnógrafos dogonosos" do sistema colonial (...)"

No mesmo artigo, na página 767:

Onde se lê:

(...) Os mesmos franceses e seus historiadores e outros "etnólogos dogonosos (...)"

Leia-se:

(...) Os mesmos franceses e seus historiadores e outros "etnógrafos dogonosos (...)"

No mesmo artigo, na nota de rodapé 45 , página 763 :

\section{Onde se lê:}

45: "O termo era de fato a associação das palavras 'Kongo '(para os habitantes do Congo 'francês') e 'Wara', nome genérico que serve no vocabulàrio corrente nos dois Congos para designar as pessoas oriundas da Africa ocidental; mas neste caso concreto, o termo designava especificamente gente oriunda da região do Tchad (antigo Chari, parte da antiga Africa equatorial francesa). Esta combinação das duas designações refletia, de fato, a larga coalizão guerreira que acabou por estabelecer-se nesta insurreição anticolonial."

\section{Leia-se:}

45 "A guerra de Kongo-Wara (ou "guerra de enxada") foi uma rebelião anticolonial com características messiânicas, liderada por Karnou. Este fez da enxada seu símbolo de luta, e exortava os seus adeptos e combatentes supostamente com as seguintes palavras, tais como retranscritas em língua francesa nos arquivos coloniais: "Matais, comeis vosso gado, repudiais vossas esposas, queimeis vossas casas, corteis as pontes, tudo que tenha tido contacto com o Branco é impuro e deve desaparecer (...) Tomeis meu medicamento, o Kougowara e eu estarei ao lado de quem quer que o tenha pendurado ao seu pescoço, e tornar-lhes-ei invisível e invulnerável". Tradução minha. Ver: DUBOIS, Colette. Le prix d'une guerre: deux colonies pendant la Première Guerre Mondiale (Gabon - OubanguiChari) (1911-1923). Thèse de doctorat 3ème cycle d'histoire. Université de Provence, Aix-en-Provence, Institut d'Histoire des Pays d'Outre-Mer, 1986, p.449-345. Section II, 2ème Partie, Chapitre I, p.166." 